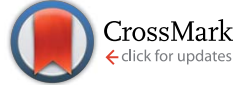

Cite this: RSC Adv., 2016, 6, 57117

\title{
Unexpected LCST-type phase behaviour of a poly(vinyl thiazolium) polymer in acetone $\uparrow$
}

\author{
Konrad Grygiel, ${ }^{a}$ Weiyi Zhang, ${ }^{a}$ Christophe Detrembleur ${ }^{\mathrm{b}}$ and Jiayin Yuan ${ }^{\star a}$
}

Received 7th April 2016

Accepted 30th May 2016

DOI: $10.1039 / c 6 r a 09023 k$

www.rsc.org/advances

We report on an unexpected lower critical solution temperature (LCST)-type phase transition of a poly(vinyl thiazolium) polymer in acetone solution, which was synthesized via radical polymerization of its corresponding ionic monomer bearing no thermoresponsiveness in acetone. The phase transition temperature can be conveniently varied by polymer concentration, ionic strength and addition of a cosolvent.

Stimuli-responsive polymers are a group of "smart" macromolecules that are able to switch between different states in response to certain alterations in the environment. Such transitions are often highly selective and can reversibly respond to subtle perturbations in a specific and precise manner. Research of such materials is not only driven by scientific curiosity, but is also important for various potential applications, including drug delivery, separation, (bio)sensing, catalysis, and "smart" coatings, to just name a few. ${ }^{1}$

Polymers exhibiting lower critical solution temperature (LCST) are a subclass of these systems and their stimuliresponsive character in solution can be often macroscopically observed as a thermally triggered aggregation of polymer chains above a specific temperature (defined as a cloud point temperature $-T_{\mathrm{c}}$ ). Such a reversible behavior can be easily manipulated since the control of temperature is less complicated in lab than tuning other environmental parameters, such as $\mathrm{pH}$, humidity, or pressure. Poly( $N$-isopropylacrylamide) (PNIPAM) is to date the most commonly studied LCST-type polymer in aqueous phase. Its popularity stems from phase transition near body temperature, which is adjustable by the incorporation of comonomers of different hydrophilicity/hydrophobicity. Nevertheless, other

${ }^{a}$ Department of Colloid Chemistry, Max Planck Institute of Colloids and Interfaces, Am Mühlenberg 1 OT Golm, D-14476 Potsdam, Germany. E-mail: Jiayin.Yuan@mpikg. mpg:de

${ }^{b}$ Center for Education and Research on Macromolecules (CERM), Chemistry Department, University of Liege (ULg), Sart-Tilman, B6a, 4000 Liege, Belgium

$\dagger$ Electronic supplementary information (ESI) available: Materials and instruments, experimental details, and additional characterization. See DOI: $10.1039 /$ c6ra09023k
LCST-type polymers have been investigated due to some restricted features of PNIPAM, such as its questionable biocompatibility, phase transition hysteresis, and a significant influence from the end group. ${ }^{2}$ These polymers include poly( $N$-vinylalkylamide), lactam/pyrrolidone/pyrrolidine based polymers, poly(dimethylaminoethyl methacrylate), polyoxazolines, and poly(alkyloxide) copolymers, which are dominantly neutral or weakly charged in solution. ${ }^{2}$

Ionic polymers are often intrinsically responsive towards stimuli such as $\mathrm{pH}$ or ionic strength. ${ }^{3-5}$ To be thermo-responsive, they often require extra structure designs to finely balance the polymer-polymer and polymer-solvent interaction. ${ }^{6-12}$ Several research groups succeeded in different ways in synthesizing ionic polymers exhibiting LCST-type phase transition in aqueous solutions. A simple, effective approach was to copolymerize ionic monomers with comonomers, such as NIPAM or propylene oxide (PO), whose polymers are known to be thermoresponsive. ${ }^{13-17}$ The ionic part of these copolymers renders, exemplarily, a strong interaction with surfaces of different materials, while PNIPAM or PPO units make them vulnerable to thermal triggers. An alternative approach encompasses the design of intrinsically thermoresponsive ionic homopolymers. The reported polyanions were typically based on the structure of poly(styrene sulfonate) or poly(3-sulfopropylmethacrylate). ${ }^{18-21}$ In the case of LCST-type water-soluble polycations, the common ones are polytetraalkylphosphonium or polytetraalkylammonium. ${ }^{22-25}$ It should be mentioned that supramolecular interactions have also been applied to endow ionic polymers with thermoresponsive function. ${ }^{26}$

Ionic polymers with LCST-type phase transition in organic solvents are comparably less studied and only a few polycations have been reported. ${ }^{11,27-29}$ The reason might be related to the difference in intermolecular interaction in organic media and in aqueous phase. In organic media, hydrogen bonding and hydrophobic interactions can be seriously weakened and even cancelled. Aoshima et al. demonstrated that certain poly(vinyl ether)s with imidazolium salts as pendant groups exhibit LCST-type phase transition in chloroform, tetrahydrofuran and 
acetone. ${ }^{27,29}$ In the other study, Luis et al. presented chiral ionic homopolymers bearing imidazolium moieties which show LCST-type behavior in chloroform-ethanol mixtures. ${ }^{28}$

Recently, our group expanded the structural toolbox of thiazolium polymers, a class of ionic polymers that has been so far rarely studied. From a chemical structure point of view, compared to common imidazolium polymers, in the case of the thiazolium polymers a nitrogen atom is simply replaced by sulfur in the heterocyclic cation ring. ${ }^{3}$ This tiny structural variation alters to some extent their chemical and physical profile and expands property window. We previously reported that the thiazolium polymers possess tunable physical properties and serve as excellent stabilizers for carbon nanotubes and as binders in electrodes of lithium ion batteries. ${ }^{30,31}$ In spite of these primary achievements, novel properties and functions are expected to emerge from this group of polymers. Herein, we report the synthesis of a vinylthiazolium-type polymer bearing a hexafluorophosphate anion $\left(\mathrm{PF}_{6}{ }^{-}\right)$, poly(4-methyl-5vinylthiazolium hexafluorophosphate) $\left[\mathrm{P}\left(\mathrm{MVTh}^{+} \mathrm{PF}_{6}{ }^{-}\right)\right]$, which exhibits an usual LCST-type phase behavior in acetone.

The synthetic method for the thermoresponsive vinylthiazolium polymer is depicted in Fig. 1. Initially, a vinylthiazolium-type monomer bearing iodide as counterion $\left(\mathrm{MVTh}^{+} \mathrm{I}^{-}\right)$was synthesized, according to our previously reported procedure, in a quaternization reaction of 4-methyl-5vinyl thiazole (MVTh) with methyl iodide. ${ }^{31}$ The successful synthesis of $\mathrm{MVTh}^{+} \mathrm{I}^{-}$was confirmed via proton nuclear magnetic resonance $\left({ }^{1} \mathrm{H}-\mathrm{NMR}\right)$ and carbon nuclear magnetic resonance $\left({ }^{13} \mathrm{C}-\mathrm{NMR}\right.$ ) spectroscopy (Fig. S1A, B and S2A, B $\dagger$ ), respectively. Consequently, the iodide monomer was subjected to an anion exchange reaction with potassium hexafluorophosphate in water, yielding a hydrophobic monomer $\left(\mathrm{MVTh}^{+} \mathrm{PF}_{6}{ }^{-}\right)$that precipitated out of water. The incorporation of $\mathrm{PF}_{6}{ }^{-}$anions was confirmed by ATR/FTIR spectroscopy (Fig. 2A). Iodide counterion of $\mathrm{MVTh}^{+} \mathrm{I}^{-}$is silent in the IR range. Hence, in the IR spectrum of $\mathrm{MVTh}^{+} \mathrm{I}^{-}$only the thiazolium cation is responsible for the recorded absorption pattern. When exchanging iodide to $\mathrm{PF}_{6}{ }^{-}$a strong band at $823 \mathrm{~cm}^{-1}$ appears and can be attributed to antisymmetric stretching of $\mathrm{PF}_{6}{ }^{-}$. A further titration test using silver nitrate confirms the quantitative replacement of iodide by $\mathrm{PF}_{6}{ }^{-}$.

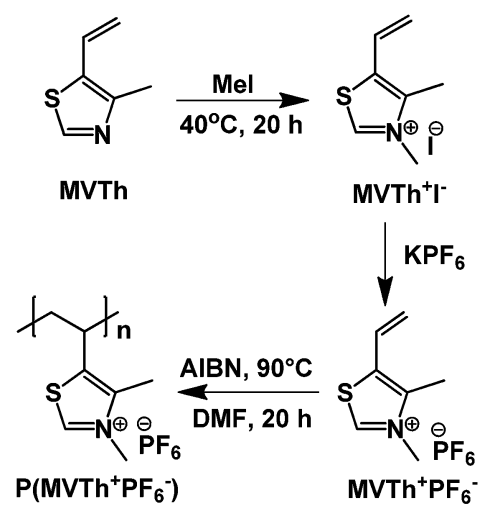

Fig. 1 Synthetic route towards $\mathrm{P}\left(\mathrm{MVTh}^{+} \mathrm{PF}_{6}{ }^{-}\right)$by radical polymerization of ionic monomer $\mathrm{MVTh}^{+} \mathrm{PF}_{6}{ }^{-}$.

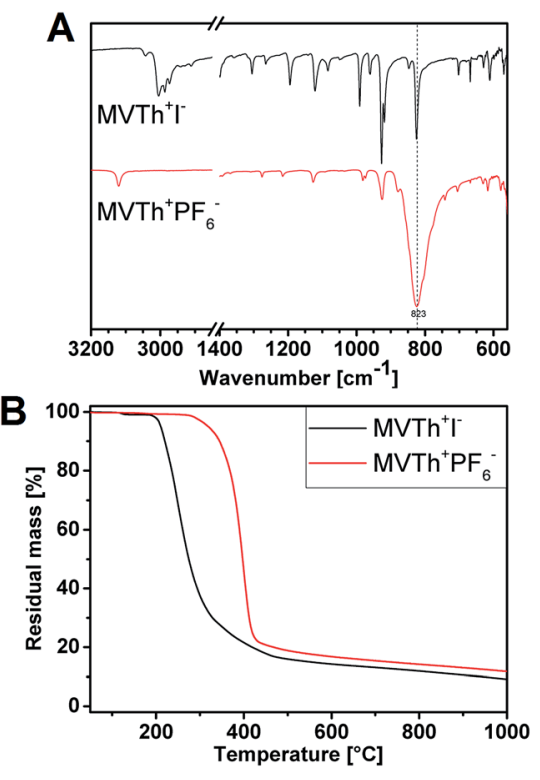

Fig. 2 (A) ATR/FTIR spectra. (B) TGA curves (recorded under $\mathrm{N}_{2}$, at a heating rate of $10 \mathrm{~K} \mathrm{~min}^{-1}$ ) of $\mathrm{MVTh}^{+} \mathrm{I}^{-}$and $\mathrm{MVTh}^{+} \mathrm{PF}_{6}{ }^{-}$, respectively.

In the final step, $\mathrm{MVTh}^{+} \mathrm{PF}_{6}{ }^{-}$was radically polymerized in dimethylformamide (DMF) to produce the targeted ionic polymer $\mathrm{P}\left(\mathrm{MVTh}^{+} \mathrm{PF}_{6}{ }^{-}\right)$. The successful polymerization is accompanied by the disappearance of the ${ }^{1} \mathrm{H}$-NMR signals of the vinyl protons (at 7.16, 6.03, and $5.69 \mathrm{ppm}$ ), which after polymerization are bound to $\mathrm{sp}^{3}$ carbons in the polymer backbone and appear at the high field (Fig. S1C and $\mathrm{D} \dagger$ ). The disappearance of vinyl group was also confirmed by ${ }^{13} \mathrm{C}-\mathrm{NMR}$ spectroscopy (Fig. S2C and $\mathrm{D}^{\dagger}$ ). The apparent number-average molecular weight is determined by gel permeation chromatography to be $19 \mathrm{kDa}$ with a dispersity index of 2.6.

Anion exchange typically has a significant effect on the thermal properties of ionic monomers and polymers. In the case of thiazolium monomers, substituting $\mathrm{PF}_{6}{ }^{-}$for $\mathrm{I}^{-}$ improves thermal stability. The ionic monomer $\mathrm{MVTh}^{+} \mathrm{PF}_{6}{ }^{-}$ decomposes at $345{ }^{\circ} \mathrm{C}$ (determined as temperature of $10 \%$ mass loss, Fig. 2B), which is $125^{\circ} \mathrm{C}$ higher than $\mathrm{MVTh}^{-} \mathrm{I}^{+}$. This is in agreement with our previous reports that thiazolium monomers having large-sized fluorinated counterions as weaker nucleophiles exhibit remarkably better thermal stability than their halide-containing precursors. $^{31}$ Surprisingly, in terms of thermal stability, $\mathrm{MVTh}^{+} \mathrm{PF}_{6}{ }^{-}$slightly outperforms its polymer $\left(310{ }^{\circ} \mathrm{C}\right.$, Fig. S3†). We also subjected $\mathrm{MVTh}^{+} \mathrm{I}^{-}$and $\mathrm{MVTh}^{+} \mathrm{PF}_{6}{ }^{-}$ to differential scanning calorimetry (DSC) measurement, detecting their melting points at $123^{\circ} \mathrm{C}$ and $137^{\circ} \mathrm{C}$, respectively (Fig. S4†).

Anion exchange can strongly affect hydrophilicity/ hydrophobicity of ionic monomers and polymers. ${ }^{3}$ In this work, the solubility of $\mathrm{MVTh}^{+} \mathrm{PF}_{6}{ }^{-}$and $\mathrm{P}\left(\mathrm{MVTh}^{+} \mathrm{PF}_{6}{ }^{-}\right)$in a wide range of solvents was tested at ambient condition and compared with their $\mathrm{I}^{-}$counterparts (Table 1). ${ }^{31}$ Polar organic solvents of high boiling point, such as DMF and DMSO, are in general good solvents and ethyl acetate (EtOAc) and chloroform $\left(\mathrm{CHCl}_{3}\right)$ are bad solvents for all the samples, independent on 
Table 1 Solubility table of vinylthiazolium monomers and polymers in various solvents ("+" soluble at 1 wt $\%$, "+/ $-"$ at $0.1-1$ wt\%, " $-"$ insoluble at $0.1 \mathrm{wt} \%)$

\begin{tabular}{llllllll}
\hline Compound & $\mathrm{H}_{2} \mathrm{O}$ & $\mathrm{MeOH}$ & Acetone & THF & ACN & DMF/DMSO $^{\text {EtOAc/CHCl }}$ \\
\hline $\mathrm{MVTh}^{+} \mathrm{I}^{-}$ & + & + & - & - & - & + & - \\
$\mathrm{MVTh}^{+} \mathrm{PF}_{6}^{-}$ & - & $+/-$ & + & $+/-$ & + & + & + \\
$\mathrm{P}\left(\mathrm{MVTh}^{+} \mathrm{PF}_{6}{ }^{-}\right)$ & - & - & + & - & + & + & -
\end{tabular}

the anion type. $\mathrm{MVTh}^{+} \mathrm{I}^{-}$is overall hydrophilic and soluble in water and methanol $(\mathrm{MeOH})$, while $\mathrm{MVT}^{+} \mathrm{PF}_{6}{ }^{-}$turns insoluble in water and only slightly soluble in $\mathrm{MeOH} . \mathrm{MVT}^{+} \mathrm{PF}_{6}{ }^{-}$is fairly soluble in other common organic solvents of low boiling point, such as acetone and acetonitrile (ACN), but a limited solubility in tetrahydrofuran (THF) was observed. Its polymer is soluble in acetone and ACN.

The uniqueness of the herein presented thiazolium polymer over its previously reported counterparts stems from the unexpected stimuli-responsive behaviour in acetone solution. At an elevated temperature, $\mathrm{P}\left(\mathrm{MVTh}^{+} \mathrm{PF}_{6}{ }^{-}\right)$undergoes thermally triggered aggregation and precipitation in acetone, i.e. LCST-type phase transition, at $T_{\mathrm{c}}$ (defined as the temperature at $80 \%$ transmittance at $\lambda=700 \mathrm{~nm}$ ). It is worth mentioning that LCSTtype phase transition is so far observed in polymers with imidazolium, pyridinium, tetraalkylphosphonium and tetraalkyammonium cations in their repeating units. The current example is the first reported in the poly(vinyl thiazolium) family, which bears a LCST-type phase behavior in acetone. ${ }^{6}$ Additionally, some recently observed LCST-type polycations were discovered actually from their corresponding thermoresponsive monomers in the same solvent. It becomes a popular trend to screen LCST-type ionic monomers to find ionic polymers bearing the same solution property. Our example here indicates that LCST-type ionic polymers do not necessarily require their monomeric species to be thermoresponsive.

In the turbidity test, $T_{\mathrm{c}}$ of $\mathrm{P}\left(\mathrm{MVTh}^{+} \mathrm{PF}_{6}{ }^{-}\right)$exhibits concentration-dependence (Fig. $3 \mathrm{~A}$ and B). At $5 \mathrm{wt} \% T_{\mathrm{c}}$ is $33{ }^{\circ} \mathrm{C}$ with a sharp phase transition. At lower polymer concentrations, $T_{\mathrm{c}}$ gradually increases and is accompanied by a noticeable broadening in phase transition. At the lowest concentration measured here at $1 \mathrm{wt} \%, T_{\mathrm{c}}$ is $47^{\circ} \mathrm{C}$ with a transmittance of $30 \%$ at $55{ }^{\circ} \mathrm{C}$, which is the upper liquid temperature of acetone. The

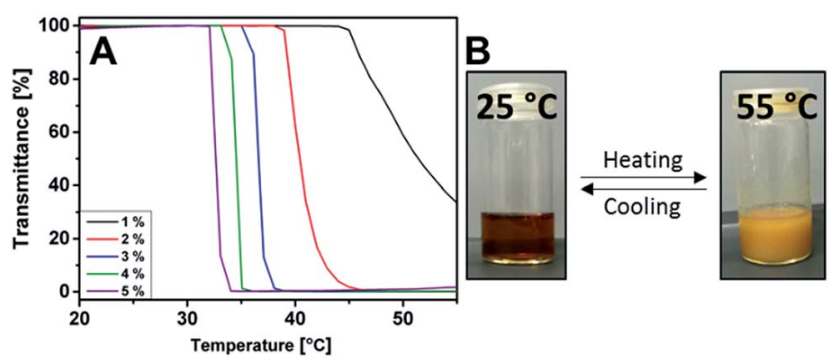

Fig. 3 (A) Turbidity curves for acetone solutions of $\mathrm{P}\left(\mathrm{MVTh}^{+} \mathrm{PF}_{6}{ }^{-}\right)$ measured at various polymer concentration. (B) Photographs of a $\mathrm{P}\left(\mathrm{MVTh}^{+} \mathrm{PF}_{6}{ }^{-}\right)$solution in acetone at $3 \mathrm{wt} \%$ below $T_{\mathrm{c}}$ (left) and above $T_{\mathrm{C}}$ (right). dependence of $T_{\mathrm{c}} \mathrm{S}$ on polymer concentration can be associated with the turbidity method, in which higher polymer concentrations trigger faster nucleation and produce more macroscopically detectable aggregates at the same given transition temperature. ${ }^{32}$ This behavior is commonly observed for the polymer-solvent systems showing LCST-type phase transition at the polymer concentrations lower than the critical concentration. ${ }^{33}$

The $T_{\mathrm{c}} \mathrm{s}$ of $\mathrm{P}\left(\mathrm{MVTh}^{+} \mathrm{PF}_{6}{ }^{-}\right)$solutions can be tuned by addition of external salts as well. Here, three salts, lithium bis(trifluoromethane sulfony)imide (LiTFSI), potassium hexafluorophosphate $\left(\mathrm{KPF}_{6}\right)$, and lithium tetrafluoroborate $\left(\mathrm{LiBF}_{4}\right)$ were tested at a polymer concentration of $3 \mathrm{wt} \%$. The concentration of the given salts in the final solutions varied from 0.001 to $0.01 \mathrm{M}$, except for $\mathrm{LiBF}_{4}$ from 0.001 to $0.008 \mathrm{M}$ due to its limited solubility in acetone (Fig. $4 \mathrm{~A}$ and $\mathrm{S} 5-\mathrm{S} 7 \dagger$ ). It is observed that addition of LiTFSI increases $T_{\mathrm{C}} \mathrm{S}$ from $37^{\circ} \mathrm{C}$ (pure polymer solution) to $45^{\circ} \mathrm{C}$ (at $0.01 \mathrm{M}$ LiTFSI). By contrast, the presence of $\mathrm{KPF}_{6}$ and $\mathrm{LiBF}_{4}$ decreases $T_{\mathrm{c}} \mathrm{s}$. In the case of $\mathrm{KPF}_{6}$, a gradual decrease in $T_{\mathrm{c}}$ down to $30{ }^{\circ} \mathrm{C}$ at $0.01 \mathrm{M} \mathrm{KPF}_{6}$ occurs. $T_{\mathrm{c}}$ seems more sensitive towards the addition of $\mathrm{LiBF}_{4}$ (down to $23{ }^{\circ} \mathrm{C}$ at $0.008 \mathrm{M} \mathrm{LiBF}_{4}$ ). This behavior is understandable since typically phase transition strongly depends on the solvophilicity/ solvophobicity balance of the polymer as well as the ionic strength. ${ }^{28}$ The noticed change in $T_{\mathrm{c}} \mathrm{s}$ results from the common salting-out effect (governed by the solubility product law) and the anion exchange effect which alters solvophobicity of the polymer. In the case of $\mathrm{KPF}_{6}$, variation in $T_{\mathrm{c}}$ is purely driven by salting-out effect, as the anions are identical. As for LiTFSI and $\mathrm{LiBF}_{4}$, the salting-out effect is accompanied by the competing anion exchange event. From our previous experiments, it is known that $\mathrm{P}\left(\mathrm{MVTh}^{+} \mathrm{BF}_{4}^{-}\right)$is insoluble in acetone (thus "acetone-phobic") while $\mathrm{P}\left(\mathrm{MVTh}^{+} \mathrm{TFSI}^{-}\right)$is fairly soluble in acetone (thus "acetone-philic"). Thereby, it is understandable that $\mathrm{P}\left(\mathrm{MVTh}^{+} \mathrm{PF}_{6}^{-}\right)$solution which undergoes partial anion
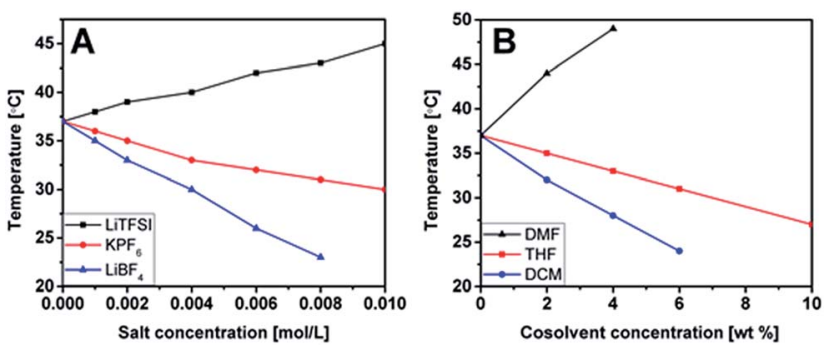

Fig. $4 T_{\mathrm{C}} \mathrm{s}$ measured in a $3 \mathrm{wt} \% \mathrm{P}\left(\mathrm{MVTh}^{+} \mathrm{PF}_{6}{ }^{-}\right)$solutions in acetone: (A) at different concentrations of external salts; (B) at different concentration of cosolvents. 
exchange with $\mathrm{LiBF}_{4}$ or LiTFSI, contains partial $\mathrm{P}\left(\mathrm{MVTh}^{+} \mathrm{BF}_{4}{ }^{-}\right)$ and $\mathrm{P}\left(\mathrm{MVTh}^{+} \mathrm{TFSI}^{-}\right)$units, respectively. Therefore, the former polymer turns less soluble and precipitates out at lower $T_{\mathrm{c}} \mathrm{s}$, while the latter exhibits the opposite effect, showing increased solubility in acetone (consequently precipitation caused by salting-out effect is only visible at higher $T_{\mathrm{c}} \mathrm{s}$ ).

Solvophobic interactions (apart from coulombic interactions) play an important role in LCST behavior of ionic polymers. ${ }^{34-36}$ Therefore, we explored the possibility of tuning solute/solvent interactions by the addition of a cosolvent to acetone to impact the $T_{\mathrm{c}} \mathrm{S}$ of $\mathrm{P}\left(\mathrm{MVTh}^{+} \mathrm{PF}_{6}{ }^{-}\right)$solutions. A $3 \mathrm{wt} \%$ $\mathrm{P}\left(\mathrm{MVTh}^{+} \mathrm{PF}_{6}{ }^{-}\right)$solution in acetone was used as a reference and three common organic solvents, THF, DMF, and dichloromethane (DCM) were tested as the additives (Fig. 4B and S8$\mathrm{S} 10 \dagger)$. DMF is a good solvent for $\mathrm{P}\left(\mathrm{MVTh}^{+} \mathrm{PF}_{6}{ }^{-}\right)$. It is expected that the addition of DMF will promote solute/solvent interactions due to the increased solvophilicity of $\mathrm{P}\left(\mathrm{MVTh}^{+} \mathrm{PF}_{6}{ }^{-}\right)$to the solvent mixture and possible hydrogen bonding between the $\mathrm{C} 2$ proton of the thiazolium ring and solvent molecules. It is indeed the case, since addition of 2 and $4 \mathrm{wt} \%$ of DMF resulted in the $T_{\mathrm{c}}$ elevated from $37^{\circ} \mathrm{C}$ (the reference sample) up to 43 and $49{ }^{\circ} \mathrm{C}$, respectively. At $6 \mathrm{wt} \% T_{\mathrm{c}}$ goes beyond the investigated temperature range. Oppositely, $T_{\mathrm{c}} \mathrm{s}$ decrease by mixing the polymer solution with a poor solvent, such as THF and DCM. With the addition of THF, a gradual downturn of $T_{\mathrm{c}}$ is detected $\left(T_{\mathrm{c}} \sim 31^{\circ} \mathrm{C}\right.$ at $6 \mathrm{wt} \%$ and $27^{\circ} \mathrm{C}$ at $10 \mathrm{wt} \%$ of THF). The analogous but more pronounced behaviour is observed when DCM, a nonsolvent for $\mathrm{P}\left(\mathrm{MVTh}^{+} \mathrm{PF}_{6}{ }^{-}\right)$, is used as a cosolvent additive $\left(T_{\mathrm{c}} \sim\right.$ $24{ }^{\circ} \mathrm{C}$ at $6 \mathrm{wt} \%$ of $\left.\mathrm{DCM}\right)$.

\section{Conclusions}

In summary, for the first time a poly(vinyl thiazolium) polymer was reported to present a LCST-type phase transition in acetone. The phase transition varies from room temperature to the boiling point of acetone in response to alterations in the polymer concentration and the addition of salts or cosolvents. The findings in this work introduce above all a new thermoresponsive ionic polymer structure and additionally offer a model system to analyze the polymer-solvent interaction that is of future research interest. The work also announces that LCSTtype ionic polymers may be prepared from a monomer nonthermoresponsive in the same solvent.

\section{Acknowledgements}

The authors acknowledge financial support from the Max Planck Society and the Marie Curie Actions of EU's $7^{\text {th }}$ Framework Program (REA grant agreement no. 289347). C. D. is Research Director by F. R. S.-FNRS and thanks FNRS for financial supports.

\section{Notes and references}

1 M. A. C. Stuart, W. T. S. Huck, J. Genzer, M. Muller, C. Ober, M. Stamm, G. B. Sukhorukov, I. Szleifer, V. V. Tsukruk,
M. Urban, F. Winnik, S. Zauscher, I. Luzinov and S. Minko, Nat. Mater., 2010, 9, 101-113.

2 D. Roy, W. L. A. Brooks and B. S. Sumerlin, Chem. Soc. Rev., 2013, 42, 7214-7243.

3 D. Mecerreyes, Prog. Polym. Sci., 2011, 36, 1629-1648.

4 M. Geoghegan, L. Ruiz-Perez, C. C. Dang, A. J. Parnell, S. J. Martin, J. R. Howse, R. A. L. Jones, R. Golestanian, P. D. Topham, C. J. Crook, A. J. Ryan, D. S. Sivia, J. R. P. Webster and A. Menelle, Soft Matter, 2006, 2, 10761080.

5 C. Chassenieux and C. Tsitsilianis, Soft Matter, 2016, 12, 1344-1359.

6 Y. Kohno, S. Saita, Y. Men, J. Yuan and H. Ohno, Polym. Chem., 2015, 6, 2163-2178.

7 X. Han, Z. Xiong, X. Zhang and H. Liu, Soft Matter, 2015, 11, 2139-2146.

8 S. T. Hemp, A. E. Smith, W. C. Bunyard, M. H. Rubinstein and T. E. Long, Polymer, 2014, 55, 2325-2331.

9 H. Yoshimitsu, E. Korchagina, A. Kanazawa, S. Kanaoka, F. M. Winnik and S. Aoshima, Polym. Chem., 2016, 7, 20622068.

10 J. Zhang, J. Liu, Y. Zuo, R. Wang and Y. Xiong, Molecules, 2015, 20, 17378.

11 Y. Xiong, J. Liu, Y. Wang, H. Wang and R. Wang, Angew. Chem., Int. Ed., 2012, 51, 9114-9118.

12 E. Karjalainen, V. Aseyev and H. Tenhu, Macromolecules, 2014, 47, 7581-7587.

13 N. Weber, J. Texter and K. Tauer, Macromol. Symp., 2011, 302, 224-234.

14 J. Texter, V. A. Vasantha, R. Crombez, R. Maniglia, L. Slater and T. Mourey, Macromol. Rapid Commun., 2012, 33, 69-74.

15 Y. Zuo, N. Guo, Z. Jiao, P. Song, X. Liu, R. Wang and Y. Xiong, J. Polym. Sci., Part A: Polym. Chem., 2016, 54, 169-178.

16 E. Karjalainen, N. Chenna, P. Laurinmaki, S. J. Butcher and H. Tenhu, Polym. Chem., 2013, 4, 1014-1024.

17 A. Tudor, L. Florea, S. Gallagher, J. Burns and D. Diamond, Sensors, 2016, 16, 219.

18 Y. Kohno and H. Ohno, Aust. J. Chem., 2012, 65, 91-94.

19 Y. Men, X.-H. Li, M. Antonietti and J. Yuan, Polym. Chem., 2012, 3, 871-873.

20 Y. Kohno, Y. Deguchi and H. Ohno, Chem. Commun., 2012, 48, 11883-11885.

21 B. Ziolkowski and D. Diamond, Chem. Commun., 2013, 49, 10308-10310.

22 Y. Men, H. Schlaad and J. Yuan, ACS Macro Lett., 2013, 2, 456-459.

23 Y. Kohno, Y. Deguchi, N. Inoue and H. Ohno, Aust. J. Chem., 2013, 66, 1393-1398.

24 G. Wang and P. Wu, Soft Matter, 2015, 11, 5253-5264.

25 W. Li and P. Wu, Polym. Chem., 2014, 5, 5578-5590.

26 O. Kretschmann, C. Steffens and H. Ritter, Angew. Chem., Int. Ed., 2007, 46, 2708-2711.

27 H. Yoshimitsu, A. Kanazawa, S. Kanaoka and S. Aoshima, Macromolecules, 2012, 45, 9427-9434.

28 S. Montolio, L. Gonzaez, B. Altava, H. Tenhu, M. I. Burguete, E. Garcia-Verdugo and S. V. Luis, Chem. Commun., 2014, 50, 10683-10686. 
29 K.-I. Seno, S. Kanaoka and S. Aoshima, J. Polym. Sci., Part A: Polym. Chem., 2008, 46, 5724-5733.

30 K. Grygiel, L. Chabanne, Y. Men and J. Yuan, Macromol. Symp., 2014, 342, 67-77.

31 K. Grygiel, J.-S. Lee, K. Sakaushi, M. Antonietti and J. Yuan, ACS Macro Lett., 2015, 4, 1312-1316.

32 Y. Men, H. Schlaad, A. Voelkel and J. Yuan, Polym. Chem., 2014, 5, 3719-3724.
33 D. J. Phillips and M. I. Gibson, Polym. Chem., 2015, 6, 10331043.

34 H. R. Dittmar and W. H. Schröer, J. Phys. Chem. B, 2009, 113, 1249-1252.

35 H. Weingärtner, T. Merkel, U. Maurer, J.-P. Conzen, H. Glasbrenner and S. Käshammer, Ber. Bunsen-Ges., 1991, 95, 1579-1586.

36 H. Weingärtner, M. Kleemeier, S. Wiegand and W. Schröer, J. Stat. Phys., 1995, 78, 169-196. 